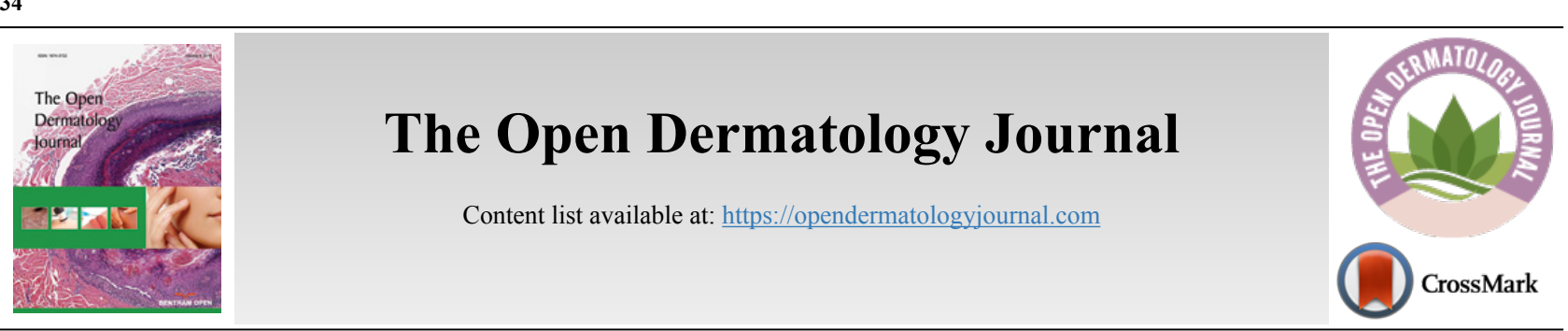

EDITORIAL

\title{
My Journey of Formulating a Patent for Topical/Spray Ivermectin Against COVID
}

\author{
Craig G. Burkhart ${ }^{1, *}$ \\ ${ }^{\prime}$ University of Toledo, College of Medicine, Toledo, Ohio, USA
}

The COVID-19 epidemic has affected almost every aspect of life on this planet. The pandemic causes each of us to cycle through the stress responses designed to protect us from such a threat.

In my case, I have been able to share my small contributions to battle this virus in The Open Dermatology Journal. I first published on how the dermatology office has to adapt to the epidemic [1]. I then wrote on the use of disinfecting masks with the SoClean CPAP sanitizer [2] This present editorial represents my last article on the trilogy and relates to my work on developing a topical/spray ivermectin to apply to the oropharynx or masks to protect one from COVID. (Note: I have written the article in such a way that one who has not pursued any medical patents may gain some insight into the thought processes involved.)

On April 6th of last year, I submitted a provisional patent on the use of topical ivermectin as a deterrent and a safety measure for the protection and prevention of COVID. The patent offered the use of ivermectin as a spray, aerosol, solution to be used for skin, oropharynx, and nostrils. It was mostly based on the theory of my previous research. The provisional would have two lives before it was put to rest.

In truth, I hoped to sell the provisional patent in its raw form to a larger company (i.e., pharmaceutical company). I have had six full patents to date, and two are related to ivermectin that I sold 15 years ago that lead to the development of a commercial product named Sklice. Fifteen years later, my contacts were not as strong. After several interviews and presentations, no one made an offer for purchase.

Ivermectin is the drug of choice for a variety of parasitic diseases, and its oral form is FDA approved for onchocerciasis and strongyloidiasis. Also, the CDC recommends the use of the oral form for scabies. It is approved for the topical treatment of

\footnotetext{
* Address correspondence to this author at the University of Toledo, College of Medicine, Toledo, Ohio, USA; Tel: 419-885-3403; Fax: 419-885-3401; E-mail: cgbakb@aol.com
}

head lice. Its usage has also been suggested for trichuriasis, ascariasis, and lymphatic filariasis. It has been used in the veterinary field since 1981. It is manufactured in pill form, drops, creams, gels, and injectable solutions.

Ivermectin is known to have anti-parasitic activity and has also been effective against a broad range of viruses, including HIV, corona 19, dengue, influenza, SARS-COV-2, and zika. The mechanism of its action is unknown, although some state that it might work to stop the virus "dampening down" the host cells' ability to clear it [3] Ivermectin inhibits IN (integrase protein) and viral cell replication and also inhibits nuclear import of host and viral proteins. It has been demonstrated to limit infection by RNA viruses such as West Nile Virus, Venezuelan equine encephalitis virus, and influenza. This broad-spectrum activity is believed to be due to the reliance of many different RNA viruses on importin (IMP alpha/Beta 1 heterodimer) responsible for integrase protein (IN) during infection. Ivermectin has antiviral action against the SARSCOV-2 clinical isolate in vitro, with a single dose able to control RNA replication within 24 to 48 hours [3]. It has been hypothesized that this is likely through inhibiting IMP alpha/beta mediated nuclear import of viral proteins, as shown for other RNA viruses. It has been suggested to give the medication early in infection to limit the viral load, prevent severe disease progression, and limit transmission. The article by Caly et al. article [3], many of its findings are stated above, was published in June 2020. However, it has been in the internet news in the first week of April, which prompted my interest in expanding the usage of ivermectin.

A provisional patent just gives one satisfaction that an idea might lead to a patentable product. My provisional patent had a few positive points that made it possibly patentable by the US Patent Office.

(1) I suggested that ivermectin is toxic to viruses directly and not via some aspect of the host's immune system. This was based on my previous work with the drug's effect on lice. Interestingly my claim was seconded by other researchers 
about 3 months later in the literature.

(2) Our patent stated that ivermectin is more lethal to viruses when in a water-in-oil base. Although this was novel when I wrote my patent on head lice, this would hopefully be seen by the patent office as a continuation of previous knowledge.

(3) There was no present patent on the use of ivermectin in sprays and other media for protection and personal use as a safety measure against COVID. Any claims regarding formulation would complement this premise. With the help of Curt Black, my pharmacologist and co-investigator in this project had formulated a spray form of ivermectin for our study purposes.

Unfortunately, our provisional also had negative points, including that we had not performed any actual research outside of formulating it into a spray form. Our patent consisted of theory rather than actual lab work. We, therefore, have no specifics or parameters, which we could document for the patent.

Some developments occurred during the year after my submission of the provisional patent. The nasal spray of ivermectin showed promising results in pigs on $26^{\text {th }}$ October, 2020. Furthermore, the US government posted studies on ivermectin nasal spray and inhaled form for COVID patients [4]. These two events seemed to make our provisional patent possibly more salable.

And so, the provisional patent seemed to have gained a second life. I did another round of calls to my connections in the drug world. I again was given an audience, but once again, no buyers.

At this time, the question arose as to whether I wanted to pursue a full patent or just call it a day. In terms of monetary costs, a provisional patent costs about $\$ 1000$, saying that one completely writes up the application (although all attorneys will feel compelled to readjust some of the verbiages).

The likelihood of getting a full patent which would give us a broad base of usage, depends upon many factors, including that no one mentions any of our patentable ideas listed above in a published article or pending patent prior to our claim date (i.e., who made a claim to the patent office first?). Secondly, it depends on the three points listed above that I had not found in my literature search. Lastly, and most importantly, the US Patent Office would hopefully not be swayed by the fact that the US Government has established two studies related to our provisional patent within months of our application date. These US Clinical Studies were posted on the internet on $11^{\text {th }}$ June, 2020. One might assume that the US government might have some documents that hinder our chances, considering their strong involvement with the posting of these studies basically only two months after we filed our provisional on $6^{\text {th }}$ April, 2020.

My experience with the US Patent office led me to conclude that they might award us a patent on the use of topical ivermectin, but they would greatly limit my usage to only the formulations which we would mention in the patent claim section of the patent. This would greatly deter pharma from purchasing (as they could easily circumvent our patent in that case). Given that assessment, I opted not to pursue a full patent but rather share my experience on the matter with the readers of my favorite journal, The Open Dermatology Journal.

\section{CONFLICT OF INTEREST}

Dr. Craig G. Burkhart is the Editor in Chief of The Open Dermatology Journal.

\section{REFERENCES}

[1] Burkhart CG. Infection control in a dermatology office during a coronavirus epidemic: Let's get down to specifics which includes the auto visitation. Open Dermatol J 2020; 14: 4-5.

[http://dx.doi.org/10.2174/1874372202014010004]

[2] Burkhart CG. Ozone disinfectants like SoClean CPAP sanitizers can be used to sterilize cloth and $\mathrm{n} 95$ masks in the protection against COVID-19. Open Dermatol J 2020; 14: 14-5. [http://dx.doi.org/10.2174/1874372202014010014]

[3] Caly L, Druce J, Catton D, Kylie AJ, Wagstaff M. The FDA-approved drug ivermectin inhibits the replication of SARS-CoV-2 in vitro Antiviral Research 2020; 178: 104787.

[4] National Institute of Health, US National Library of Medicine Usefulness of topical ivermectin and carrageenan to prevent contagion of Covid 19. Clinical Trials gov https:/clinicaltrials.gov/ct2/show/ NCT04425850

\section{C) 2021 Craig G. Burkhart}

This is an open access article distributed under the terms of the Creative Commons Attribution 4.0 International Public License (CC-BY 4.0), a copy of which is available at: https://creativecommons.org/licenses/by/4.0/legalcode. This license permits unrestricted use, distribution, and reproduction in any medium, provided the original author and source are credited. 